\title{
Isolation and Characterization of Sporobacter termitidis gen. nov., sp. nov., from the Digestive Tract of the Wood-Feeding Termite Nasutitermes lujae
}

\author{
I. GRECH-MORA, ${ }^{1,2}$ M.-L. FARDEAU, ${ }^{1}$ B. K. C. PATEL,${ }^{1,3}$ B. OLLIVIER, ${ }^{1 *}$ A. RIMBAULT, ${ }^{4}$ \\ G. PRENSIER, ${ }^{5}$ J.-L. GARCIA, ${ }^{1}$ AND E. GARNIER-SILLAM ${ }^{2}$
}

Laboratoire de Microbiologie Institut Français de Recherche Scientifique pour le Développement en Coopération (ORSTOM), Université de Provence CESB-ESIL, 13288 Marseille Cedex 9, ${ }^{1}$ Laboratoire de Biologie des Sols et des Sédiments Continentaux, Université Paris Val de Marne, 94010 Créteil Cedex, ${ }^{2}$ Laboratoire de Microbiologie, Université René Descartes, Faculté de Pharmacie, 75270 Paris Cedex 06, ${ }^{4}$ and Laboratoire de Microbiologie, Université Blaise Pascal, 63177 Aubière Cedex, ${ }^{5}$ France, and Faculty of Science and Technology, Griffith University, Brisbane, Queensland 4111, Australia ${ }^{3}$

\begin{abstract}
A new chemoorganotrophic bacterium, strain $\operatorname{SYR}^{\mathrm{T}}(\mathrm{T}=$ type strain), was isolated from the digestive tract of the wood-feeding termite Nasutitermes lujae. This organism was a slightly curved spore-forming rod-shaped bacterium. It had a gram-positive-type cell wall and was obligately anaerobic. It grew exclusively on a limited range of methylated aromatic compounds including 3,4,5-trimethoxycinnamate (TMC), sinapate (3,5-dimethoxy-4-hydroxycinnamate), 3,4-dimethoxycinnamate, 3,4,5-trimethoxybenzoate, ferulate, syringate (3,5-dimethoxy-4-hydroxybenzoate), and vanillate (4-hydroxy-3-methoxybenzoate) but not on carbohydrates, alcohols, or fatty acids. The isolate required yeast extract for growth. Strain $\mathrm{SYR}^{\mathrm{T}}$ grew optimally between 32 and $35^{\circ} \mathrm{C}$ and at $\mathrm{pH}$ values between 6.7 and 7.2 , with $\mathrm{NaCl}$ concentrations from 0 to $5 \mathrm{~g} \cdot \operatorname{liter}^{-1}$, on $\mathrm{TMC}$ with a doubling time of about $25 \mathrm{~h}$. During growth on TMC in the presence of sulfide or cysteine, dimethyl sulfide and acetate were produced, whereas methanethiol was an intermediary product of metabolism. The ring of the methoxylated aromatic compound was cleaved. The DNA base composition was $57 \mathrm{~mol} \%$ guanine plus cytosine. Comparative $16 S$ rRNA sequence analysis indicated that strain $S Y R^{T}$ was distantly related to Eubacterium desmolans and Eubacterium plautii. On the basis of its distinct phylogenetic position and physiological properties, strain SYRT has been designated a new species of a new genus, Sporobacter termitidis gen. nov., sp. nov. $\left(=\right.$ DSM $\left.10068^{\mathrm{T}}\right)$.
\end{abstract}

Termites play a major role in the tropics and the subtropics, owing to their ability to decompose plant litter. On the basis of their diet, they have been classified as wood feeders, soil feeders, and fungus growers $(20,31)$. The digestive tract of termites is colonized by a complex microbial consortium which produces acetate and other volatile fatty acids from the polysaccharide components and plant lignocellulose complexes. The volatile fatty acids (mainly acetate) are absorbed by the termites for conversion to energy $(8,38)$. Currently there is limited knowledge of the role played by the microbial consortium in the degradation of aromatic constituents of lignocellulose, including lignin $(11-13,15,16,29)$. However, several studies have indicated that oxic and anoxic conditions exist $(3,4,6$, 40). One approach useful for assessing the potential for lignin degradation is to study the degradation of lignin monomers (and related aromatic compounds) by the populations of anaerobic or aerobic bacteria present in the termite digestive tract. Brune et al. (12) have given further evidence that the aromatic compounds tested, including benzoic acid, phenolic compounds, and ferulic acid, the only monosubstituted methoxyl aromatic compound tested, were completely mineralized under oxic conditions. Furthermore, previous studies have shown that anaerobic demethylation of aromatic compounds occurs but that the aromatic ring (nucleus) is not cleaved ( 7 , 10, 29). In this metabolism, hydrogenotrophic homoacetogenic bacteria were mainly involved. However, separate studies have

\footnotetext{
* Corresponding author. Mailing address: Laboratoire de Microbiologie ORSTOM, CESB-ESIL, Case 925, 163 avenue de Luminy, 13288 Marseille Cedex 9, France. Phone: 33.91.82.85.76. Fax: 33.91.82.85.70. Electronic mail address: garcia@orstom.esil.univ-mrs.fr.
}

shown that the homoacetogen Holophaga foetida, originally isolated from anoxic freshwater mud $(2,32)$, is able to cleave the ring of methoxylated aromatic and phenolic compounds. Initially, it produces volatile sulfur compounds, methanethiol and dimethyl sulfide (DMS), by transferring the methyl group from methoxylated compounds to sulfide (used for preparing the anaerobic medium), and then the remaining aromatic residue is degraded to acetate by the phloroglucinol pathway (28). Considering the physiological properties of $H$. foetida and its activities on aromatic compounds, we tried to isolate similar anaerobic bacteria from termite hindguts.

In this paper we describe a new homoacetogenic bacterium isolated from the hindgut of the wood-feeding termite Nasutitermes lujae and designated strain $\mathrm{SYR}^{\mathrm{T}}(\mathrm{T}=$ type strain). Strain $\mathrm{SYR}^{\mathrm{T}}$ has the ability to cleave the ring of specific methoxylated aromatic compounds but not of phenolic compounds during fermentation, as described for $H$. foetida. It has been characterized as a new genus within the domain Bacteria, Sporobacter termitidis gen. nov., sp. nov.

\section{MATERIALS AND METHODS}

Source of microorganisms. Nests of the wood-feeding termite Nasutitermes lujae (family Termitidae) were collected from M'Balmayo forest (Cameroon) and maintained at $27^{\circ} \mathrm{C}$ in our laboratory. After termites had been dipped in ethanol, guts were extracted, and these served as the inoculum. Guts of 10 worker termites were removed with a pair of forceps and placed in a drop of $0.9 \% \mathrm{NaCl}$ solution. The contents were added to a tube containing $5 \mathrm{ml}$ of culture medium and transferred to an anoxic glove box (La Calhène, Bezons, France), where they were homogenized.

Culture medium. Anoxic media were prepared by the techniques of Hungate $(23,34)$. The growth medium for enrichment, isolation, and most routine culture work contained (per liter) $1.0 \mathrm{~g}$ of $\mathrm{NH}_{4} \mathrm{Cl}, 0.3 \mathrm{~g}$ of $\mathrm{K}_{2} \mathrm{HPO}_{4}, 0.3 \mathrm{~g}$ of $\mathrm{KH}_{2} \mathrm{PO}_{4}$, $0.2 \mathrm{~g}$ of $\mathrm{MgCl}_{2} \cdot 6 \mathrm{H}_{2} \mathrm{O}, 0.1 \mathrm{~g}$ of $\mathrm{CaCl}_{2} \cdot 2 \mathrm{H}_{2} \mathrm{O}, 0.1 \mathrm{~g}$ of $\mathrm{KCl}, 0.5 \mathrm{~g}$ of $\mathrm{CH}_{3} \mathrm{COONa} \cdot 3 \mathrm{H}_{2} \mathrm{O}, 0.6 \mathrm{~g}$ of $\mathrm{NaCl}, 0.5 \mathrm{~g}$ of yeast extract (Difco), $0.001 \mathrm{~g}$ of 
resazurin, $0.5 \mathrm{~g}$ of cysteine $\cdot \mathrm{HCl}, 1.5 \mathrm{ml}$ of trace element solution (24), and 3,4,5-trimethoxycinnamate (TMC). The medium was adjusted to $\mathrm{pH} 7$ with $10 \mathrm{M}$ $\mathrm{KOH}$, boiled under a stream of $\mathrm{O}_{2}$-free $\mathrm{N}_{2}$, and cooled to room temperature. Portions $(5 \mathrm{ml})$ of medium were dispensed into Hungate tubes under $\mathrm{N}_{2}-\mathrm{CO}$ (80:20) and sterilized for $45 \mathrm{~min}$ at $110^{\circ} \mathrm{C}$. A $0.05-\mathrm{ml}$ volume of a $2 \%$ $\mathrm{Na}_{2} \mathrm{~S} \cdot 9 \mathrm{H}_{2} \mathrm{O}$ solution and $0.2 \mathrm{ml}$ of a $10 \% \mathrm{NaHCO}_{3}$ solution (from sterile anaerobic solutions) were added to all the anoxic medium preparations prior to inoculation.

Nitrate, sulfur, sulfate, and thiosulfate were tested as electron acceptors in TMC-amended growth medium at a final concentration of $20 \mathrm{mM}$. Experiments were performed with strain $\mathrm{SYR}^{\mathrm{T}}$ in coculture with the hydrogenotrophic methanogen Methanospirillum hungatei in order to check for the existence of interspecies hydrogen transfer.

Growth medium that lacked TMC was used to determine the range of substrates utilized and included different aromatic compounds, carbohydrates, fatty acids, and alcohols. The test substrates were added to the medium from sterile stock solutions to give the desired concentration (between 5 and $20 \mathrm{mM}$ ).

Enrichment and isolation. Hindgut samples were inoculated into TMC-containing growth medium to initiate enrichments. After several transfers, the enrichment cultures were serially diluted and pure cultures were isolated by the roll tube technique. For preparing roll tubes, the growth medium was solidified with $1.6 \%(\mathrm{wt} / \mathrm{vol}$ ) Noble agar (Difco). After incubation, colonies that developed in the roll tube containing the most diluted enrichment inoculum were picked and the process of serial dilution in roll tubes was repeated at least twice to purify the cultures. Purity of the isolates was routinely checked by microscopical examination and by culturing in the growth medium lacking TMC but containing glucose.

Microscopy. Negative staining of cells was performed with $4 \%$ (wt/vol) uranyl acetate in distilled water. For transmission electron microscopy of thin sections, cells from an exponentially growing culture were fixed for $1 \mathrm{~h}$ in $0.07 \mathrm{M}$ sodium cacodylate buffer ( $\mathrm{pH} 7.3$ ) containing $1.2 \%$ glutaraldehyde and $0.05 \%$ ruthenium red. The samples were then washed in cacodylate buffer containing $0.05 \%$ ruthenium red, fixed in $1 \%$ (wt/vol) $\mathrm{OsO}_{4}$ in $0.07 \mathrm{M}$ cacodylate buffer, and embedded in Epon, and then sections were cut and stained first with $2 \%$ uranyl acetate in $50 \%$ ethanol and then with lead citrate (42). Micrographs were taken with a JEOL $1200 \mathrm{CX}$ electron microscope.

Phase-contrast microscopy and observation of stained cell preparations were performed by using a Nikon microscope.

Analytical techniques. Bacterial growth was measured with a Shimadzu model UV $160 \mathrm{~A}$ spectrophotometer at $660 \mathrm{~nm}$ by inserting anaerobic Hungate tubes directly into the chamber of the cuvette holder. All experiments were performed in duplicate. Total DMS in the liquid and gas phases was quantified by static headspace analysis by using the standard-addition method (39), which takes into account the matrix effect: for a given analyte, the partition coefficient is dependent on the system's thermodynamic conditions (i.e., temperature and internal pressure) and the matrix composition (25). These parameters may vary with growth conditions and/or culture medium composition.

For experiments with TMC $(21 \mu \mathrm{mol}$ per tube $)$ as the substrate, six series of equivalent tubes after bacterial growth (quintuplicates) were spiked with either $0,100,200,300,400$, or $500 \mu \mathrm{l}$ of a $0.2 \%$ (vol $/ \mathrm{vol}$ ) solution of DMS in methanol, leading to the addition of $0,2.73,5.46,8.19,10.92$, or $13.65 \mu \mathrm{mol}$ of DMS per tube, respectively. In order not to modify the phase ratio $\beta$ (gas phase volume liquid phase volume), methanol was added so that the final volume of added methanol and DMS per tube was $500 \mu \mathrm{l}$. It was assumed that before additions, all equivalent tubes were isobaric. Additions were made through the black butyl rubber septum of the Hungate tube. After equilibration of the tubes for $60 \mathrm{~min}$ in ice, a 1-ml headspace volume was sampled with a gas syringe (Dynatech Pressure Lok Precision series A-2, 1 ml; Precision Sampling Corporation, Baton Rouge, La.) fitted with a polytetrafluoroethylene valve and immediately injected into a wide-bore CP-Sil 5CB column $(25 \mathrm{~m}$ by $0.53 \mathrm{~mm}$ [outside diameter]; Chrompack, Middelburg, The Netherlands). A Girdel model 300 gas chromatograph (Girdel, Suresnes, France) was used. The oven was maintained at $15^{\circ} \mathrm{C}$ with liquid nitrogen, and the injector and flame ionization detector temperatures were 15 and $300^{\circ} \mathrm{C}$, respectively. Helium (relative inlet pressure, $60 \mathrm{kPa}$ ) was the carrier gas. Peaks were recorded with a CR-6A integrator (Shimadzu, Kyoto, Japan). Between injections, syringes were heated at $80^{\circ} \mathrm{C}$. The total amount of DMS formed by the culture is given by the intersection of the curve with the $x$ axis of the amounts of added DMS (micromoles; $x$ axis)-peak areas (microvolts - second; $y$ axis) plot.

Methanethiol was detected at $170^{\circ} \mathrm{C}$ on a Porapak $\mathrm{Q}$ column by using a Chrompack CP 9000 gas chromatograph (Chrompack France, Les Ulis, France) equipped with a flame ionization detector and $\mathrm{N}_{2}$ as the carrier gas. Acetate production was quantified by using the same column conditions as described above. Prior to analysis, culture supernatants were acidified with $\mathrm{H}_{3} \mathrm{PO}_{4}$. TMC was quantified by high-performance liquid chromatography (HPLC) by using a chromatograph (Spectra Series 100 model; Thermo Separation Products, Les Ulis, France) equipped with a $C_{18} 5-\mu m$-particle-size Kromasil column ( 250 by 4.6 [inner diameter] $\mathrm{mm}$; Touzart \& Matignon, Vitry-sur-Seine, France). The column temperature was $35^{\circ} \mathrm{C}$. An isocratic mobile phase of $50: 50$ ( $\mathrm{vol} / \mathrm{vol}$ ) acetonitrile-water was used at a flow rate of $0.7 \mathrm{ml} \mathrm{min}^{-1}$; the volume of the injection loop was $20 \mu \mathrm{l}$. TMC was quantified at $220 \mathrm{~nm}$ with a Shimadzu SPD-6A UV detector connected to a CR-6A Shimadzu integrator.

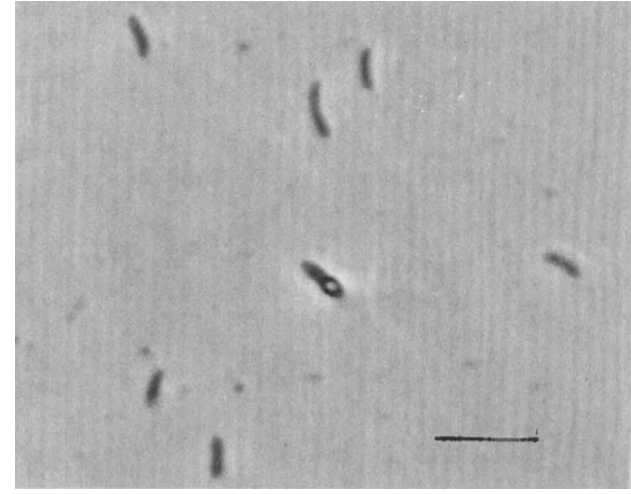

FIG. 1. Phase-contrast photomicrograph of strain $\mathrm{SYR}^{\mathrm{T}}$. Bar $=5 \mu \mathrm{m}$.

Carbohydrates, lactate, formate, pyruvate, and glycerol were analyzed by using an HPLC equipped with an ORH 801 column (Interaction Chemicals, Inc., Mountain View, Calif.) connected to a differential refractometer (Knauer, Berlin, Germany). The flow rate of sulfuric acid $(0.005 \mathrm{~N})$ was $0.6 \mathrm{ml} \mathrm{min}^{-1}$, and the volume of the injection loop was $20 \mu \mathrm{l}$. The column temperature was $35^{\circ} \mathrm{C} . \mathrm{H}_{2}$ and $\mathrm{CO}_{2}$ were measured as previously described (18).

DNA base composition. DNA was isolated and purified by chromatography on hydroxyapatite. The guanine-plus-cytosine $(\mathrm{G}+\mathrm{C})$ content was determined by HPLC, according to the method of Meshbah et al. (36). Nonmethylated Lambda DNA (Sigma) was used as the standard.

16S rRNA sequence studies. Purification of genomic DNA, amplification, and purification of the $16 \mathrm{~S}$ rRNA gene (16S rDNA) from strain $S \mathrm{YR}^{\mathrm{T}}$ were performed by using a technique described previously $(33,41)$. The purified PCR product was sequenced directly on an $\mathrm{ABI}$ automated DNA sequencer by using a Prism dideoxy terminator cycle sequencing kit and protocols recommended by the manufacturer (Applied Biosystems Ltd., Foster City, Calif.). By using the sequence editor ae2, the $16 \mathrm{~S}$ rDNA sequence of strain SYR ${ }^{\mathrm{T}}$ was aligned with the $16 \mathrm{~S}$ rDNA sequences of various members of the bacterial phyla obtained from the Ribosomal RNA Database Project (35) and from GenBank. Positions of sequence and alignment uncertainty were omitted from the analysis, and pairwise evolutionary distances for 1,128 nucleotides were computed. Phylogenetic analysis was performed by using programs which form part of the PHYLIP package and include DNADIST (Jukes and Cantor option), NEIGHBOR-JOINING, and DNAPARS (19). Tree topology was reexamined by using 100 bootstrapped data sets for which a script file with the following PHYLIP programs was used: SEQBOOT, DNADIST, FITCH, and CONSENSE. Programs in the phylogenetic package MEGA (30) were also used. PHYLIP programs were run on a Sun SPARC workstation, and MEGA was run on a Compaq notebook (model 410CX; Contura).

Nucleotide sequence accession numbers. The strain SYR $^{\mathrm{T}}$ 16S rDNA se quence which we determined has been deposited in the EMBL database under accession number $\mathrm{Z} 49863$.

\section{RESULTS}

Isolation. At least five subcultures of TMC enrichment culture were performed at $37^{\circ} \mathrm{C}$ prior to serial end point dilution in agar roll tubes. After 7 weeks of incubation, two colonies were picked and the process of end point dilution was repeated until pure cultures were obtained. As the two cultures were similar in phenotypic characteristics, viz., were nonmotile curved rods that produced acetate from TMC and were not able to ferment glucose, they were deemed to be similar and only one culture, designated SYR, was characterized further.

Cellular properties. Strain SYR ${ }^{\mathrm{T}}$ cells were slightly curved rods that were 0.3 to 0.4 by 1 to $2 \mu \mathrm{m}$ and occurred singly or in pairs (Fig. 1). They were not motile when viewed under a phase-contrast microscope, but electron microscopy of negatively stained cells revealed the presence of peritrichous flagella (Fig. 2a). Thin sections revealed an atypical gram-positive cell wall composed of a thin layer (presumably a peptidoglycan layer) and an S layer (Fig. 2b). Spores were detected but were sparse, especially in liquid cultures (Fig. 1).

Growth and metabolic properties. Strain $S Y R^{\mathrm{T}}$ was a strict anaerobe. It grew on methoxylated aromatic compounds, in- 


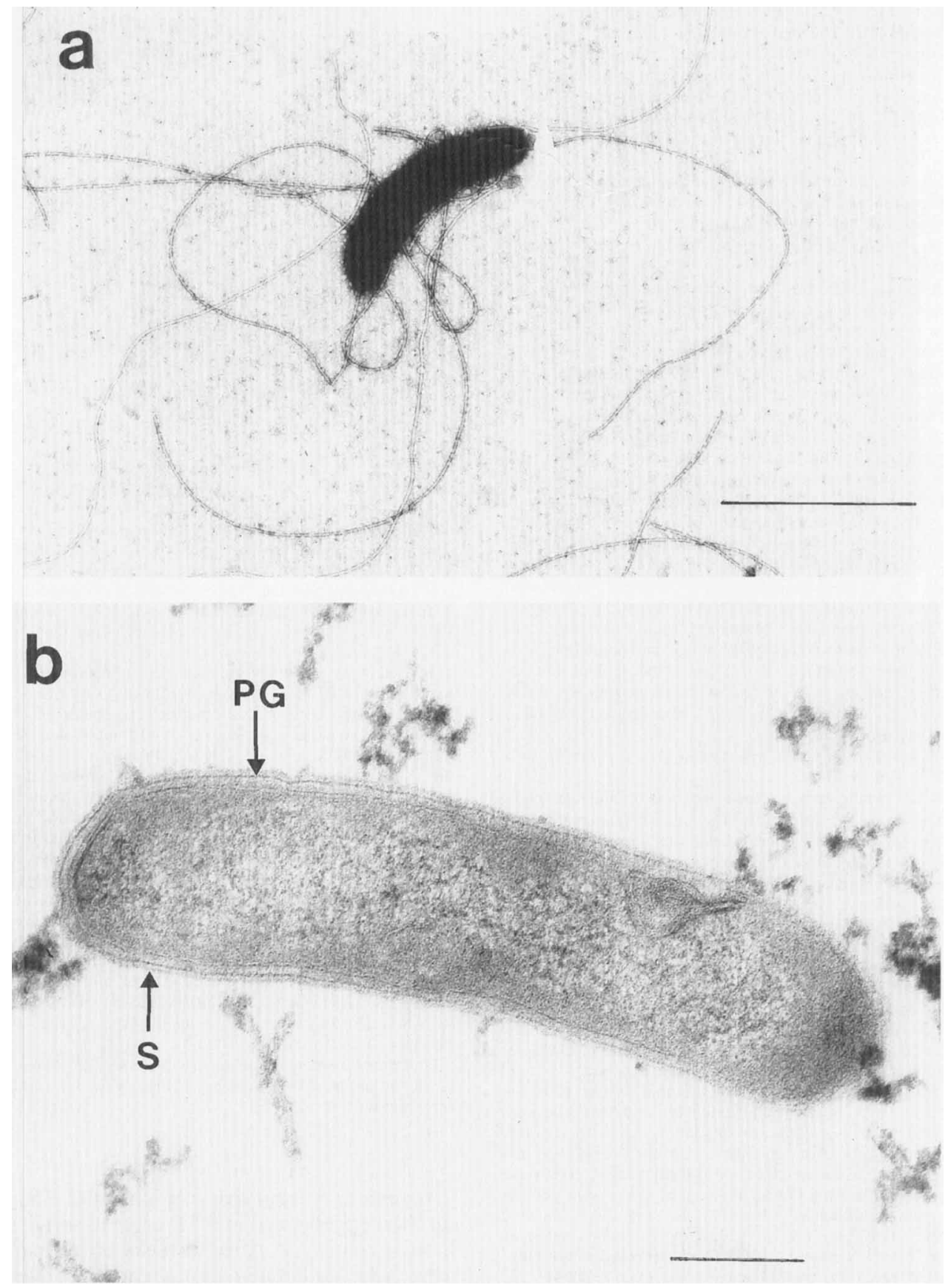

FIG. 2. (a) Electron micrograph of strain $\mathrm{SYR}^{\mathrm{T}}$ negatively stained showing peritrichous flagellation. $\mathrm{Bar}=1 \mu \mathrm{m}$. (b) Ultrathin section of strain $\mathrm{SYR} \mathrm{R}^{\mathrm{T}}$ showing the $S$ layer $(S)$ and peptidoglycan $(P G) . B a r=0.2 \mu \mathrm{m}$.

cluding TMC, sinapate (3,5-dimethoxy-4-hydroxycinnamate), 3,4-dimethoxycinnamate, 3,4,5-trimethoxybenzoate, ferulate, syringate (3,5-dimethoxy-4-hydroxybenzoate), and vanillate (4-hydroxy-3-methoxybenzoate), only in the presence of yeast extract $(0.01 \%)$. No growth was observed with the following substrates: veratrate, isovanillate, benzoate, $\beta$-resorcylate $(2,4-$ dihydroxybenzoate), gentisate (2,5-dihydroxybenzoate), vanillin (4-hydroxy-3-methoxybenzaldehyde), 4-hydroxybenzoate, 2,4,6-trihydroxybenzoate, protocatechuate, cinnamate, $p$ coumarate, 4-methoxycinnamate, pyrogallol, gallate, caffeate, phenol, $o$-cresol, $p$-cresol, catechol, salicin, arbutin, phloroglu- cinol, cyclohexanecarboxylate, hydroxycinnamate, phenylacetate $(5 \mathrm{mM})$, fructose, galactose, glucose, ribose, xylose, lactose, maltose, sucrose, trehalose, mannitol, rhamnose, sorbose, melibiose, adonitol, dulcitol, sorbitol, pyruvate (20 mM), lactate, formate $(10 \mathrm{mM})$, ethanol, methanol, glycerol $(40 \mathrm{mM})$, and $\mathrm{H}_{2}-\mathrm{CO}_{2}(80: 20$ [vol/vol]; two bars $)$. Acetate was the only end product from TMC or syringate oxidation, and $\mathrm{H}_{2}$ or $\mathrm{CO}_{2}$ was not produced. Coculture of strain $\mathrm{SYR}^{\mathrm{T}}$ and the hydrogenotrophic methanogen $M$. hungatei on methoxyaromatic compounds did not lead to methane formation, thus indicating the absence of interspecies hydrogen transfer (data not shown). 

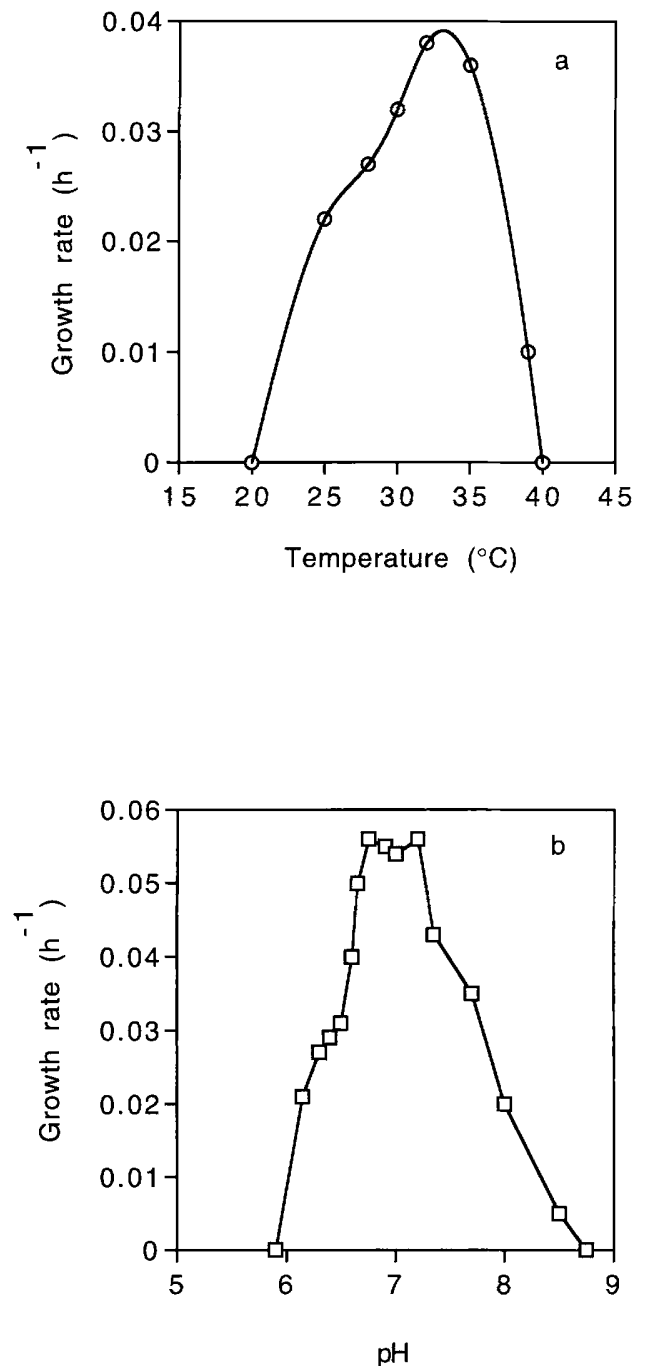

FIG. 3. Effect of temperature (a) and $\mathrm{pH}(\mathrm{b})$ on the growth of strain $\mathrm{SYR}^{\mathrm{T}}$ on TMC. Temperature experiments were performed at $\mathrm{pH} 7.0 ; \mathrm{pH}$ experiments were performed at $37^{\circ} \mathrm{C}$.

Growth required the presence of a reducing agent in the medium such as dithionite, sulfide, or cysteine. Sulfide and cysteine acted as a methyl acceptor, which resulted in the production of DMS and methanethiol as an intermediary product of metabolism. Oxidation of $5.45 \mathrm{mM}$ TMC led to the production of $20.25 \mathrm{mM}$ acetate and $0.93 \mathrm{mM}$ DMS. Nitrate, sulfur, sulfate, thiosulfate, or sulfite could not be used as an alternate electron acceptor. Strain $\mathrm{SYR}^{\mathrm{T}}$ grew between 20 and $40^{\circ} \mathrm{C}$, with the optimum around $35^{\circ} \mathrm{C}$ (Fig. 3a). The $\mathrm{pH}$ range for growth was 5.9 to 8.8 , and the optimum $\mathrm{pH}$ for growth was between 6.7 and 7.2 (Fig. 3b). Growth occurred at the same rate with $\mathrm{NaCl}$ concentrations between 0 and $5 \mathrm{~g} /$ liter, but growth inhibition occurred at concentrations of $>12.5 \mathrm{~g} \cdot \operatorname{liter}^{-1}$.

Acetate was also the major product of metabolism from sinapate, syringate, and 3,4,5-trimethoxybenzoate. The amount of TMC degraded was dependent on the initial substrate concentration in the growth medium (data not shown). For TMC concentrations of $<5.45 \mathrm{mM}$, the substrate was degraded into acetate (approximately $4 \mathrm{~mol} / \mathrm{mol}$ of TMC). At concentrations between 5.45 and $10.82 \mathrm{mM}$, approximately one-fourth of the substrate remained unused, but the amount of acetate produced per mol of TMC degraded was still approximately 4 mol.
With initial TMC concentrations higher than $10.82 \mathrm{mM}$, a greater amount of TMC remained unused and the ratio of acetate/TMC diminished to 2.57. No additional end products, however, were detected by HPLC. Initial concentrations of TMC greater than $40 \mathrm{mM}$ inhibited growth of strain SYR ${ }^{\mathrm{T}}$ completely. Optical density increased until the concentration of TMC reached $10.82 \mathrm{mM}\left(\mu=0.027 \mathrm{~h}^{-1}\right)$. The maximum growth rate was obtained in the presence of $8.39 \mathrm{mM} \mathrm{TMC}$ $\left(\mu=0.035 \mathrm{~h}^{-1}\right)$. When the organism was grown on 3,4-dimethoxycinnamate or vanillate, acetate and catechol accumulated in the medium after 3 months of incubation. Vanillate was detected as an intermediary product from 3,4-dimethoxycinnamate metabolism. After 7 weeks of incubation, acetate and vanillate were produced from ferulate degradation, ferulate being poorly used. Utilization of sulfide as a methyl acceptor resulted in production of DMS, the major volatile sulfur compound, with methanethiol being an intermediary product of metabolism. However, growth on TMC also occurred in the absence of sulfide, suggesting that $\mathrm{CO}$ derived from the $\mathrm{CO}_{2}$ of the medium probably acted as the methyl acceptor (17).

DNA base composition. The average DNA base composition of strain $\mathrm{SYR}^{\mathrm{T}}$, based on three HPLC determinations, was 57 $\mathrm{mol} \% \mathrm{G}+\mathrm{C}$.

16S rDNA sequence analysis. A sequence consisting of 1,507 bases of the $16 \mathrm{~S}$ rDNA of strain SYR ${ }^{\mathrm{T}}$ was determined. The sequence (positions 8 to 1542, Escherichia coli numbering according to the study of Winker and Woese [43]) was aligned with those of representatives of the various phyla of the domain Bacteria, and phylogenetic analysis was performed. Several data sets which included different representatives from the various phyla of the domain Bacteria were also created, and in all cases strain $S Y R^{T}$ was consistently placed as a peripheral member of cluster III, in the subbranch of the low-G + C grampositive clostridial group as defined by Collins et al. (14). Low bootstrap values were obtained with Eubacterium plautii and Eubacterium desmolans, indicating a poor relationship (Fig. 4). The evolutionary distances separating strain $\mathrm{SYR}^{\mathrm{T}}$ and its relatives and the dendrogram derived from these distances are depicted in Table 1 and Fig. 4, respectively. The G+C content of the $16 \mathrm{~S}$ rDNA of strain $\mathrm{SYR}^{\mathrm{T}}$ was calculated to be $53 \%$. Transversion analysis did not affect the relationship of strain $\mathrm{SYR}^{\mathrm{T}}$ with its nearest relatives.

\section{DISCUSSION}

The hindgut microbial consortium of wood-feeding termites, in contrast to that of soil-feeding termites, is composed of cellulose-degrading or homoacetogenic hydrogen-oxidizing bacteria such as Clostridium termitidis (22), Acetonema longum (27), and Sporomusa termitida (9). The microflora therefore contributes significantly to the overall anaerobic digestion of the ingested organic plant lignocellulosic matter. However, relatively little is known about the degradation of lignin monomers and lignin-related compounds. By using $\left[{ }^{14} \mathrm{C}\right.$-lignin $]$ lignocelluloses, Butler and Buckerfield (13) and Cookson (16) demonstrated that the ring (nucleus) was cleaved. Cookson (16) suggested that this degradation process could have been the result of the action of anaerobic bacteria. A contrasting report indicated that oxic conditions are required to completely oxidize lignin-derived phenylpropanoids and other monoaromatic compounds (12). In this paper, we report the existence, in $N$. lujae, of a strictly anaerobic bacterium that oxidizes methoxyaromatic compounds mainly into acetate, DMS and methanethiol being produced as an intermediary product of metabolism, in the presence of sulfide or cysteine. During fermentation of methoxylated aromatic substrates by strain $\mathrm{SYR}^{\mathrm{T}}$, no $\mathrm{H}_{2}$ is evolved; 


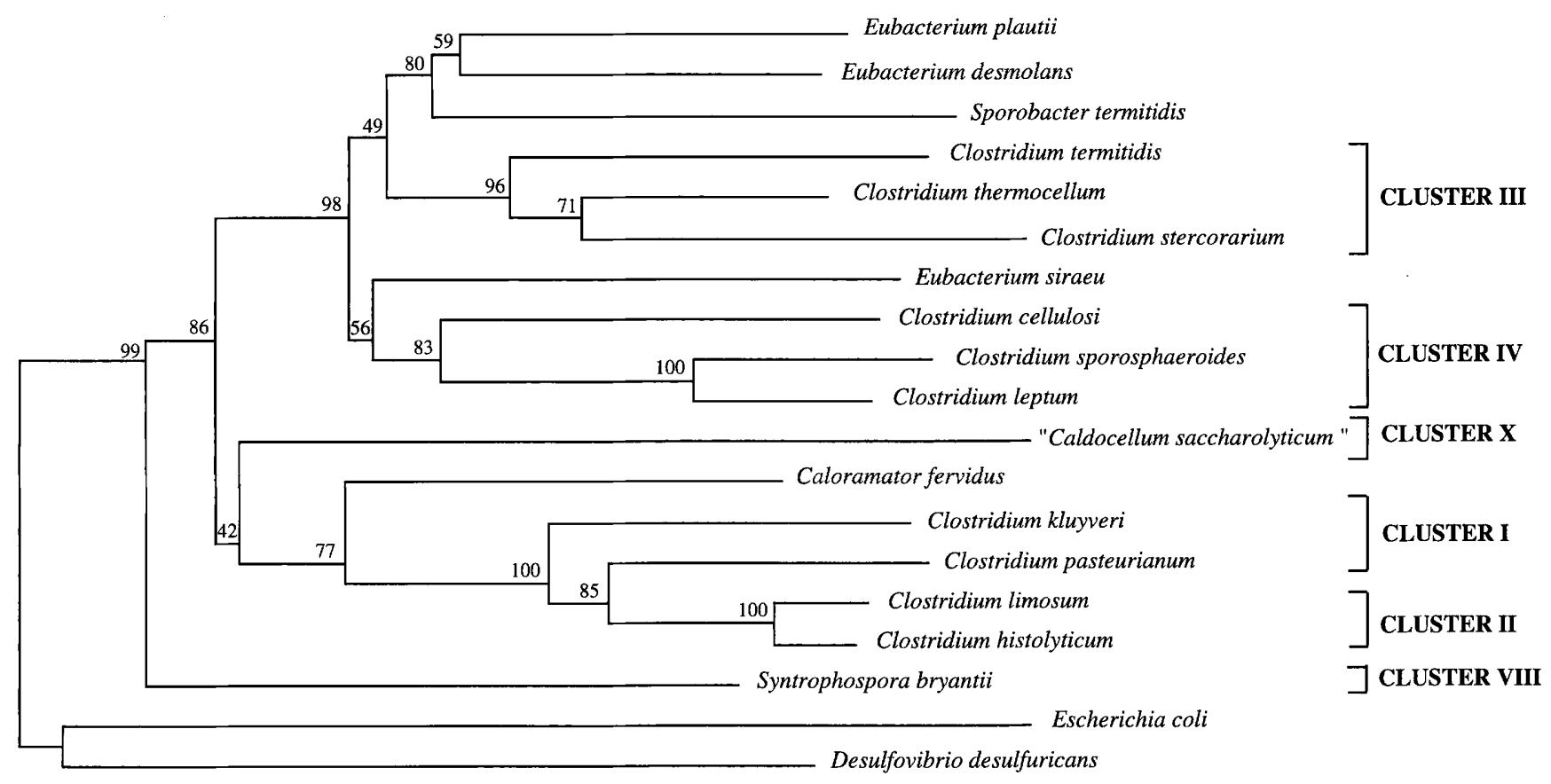

$\longdiv { 0 . 0 1 }$

FIG. 4. Dendrogram indicating the position of $S$. termitidis (strain $\mathrm{SYR}^{\mathrm{T}}$ ) among the representatives of the members of the low-G+C gram-positive clostridial groups. The numbers indicate bootstrap values from 100 data sets. The dendrogram was derived from the evolutionary distance matrix shown in Table 1.

therefore, strain $\mathrm{SYR}^{\mathrm{T}}$ does not possess any $\mathrm{H}_{2}$-evolving hydrogenase. Accordingly, no interspecies $\mathrm{H}_{2}$ transfer can result from strain SYR ${ }^{\mathrm{T}}$ 's association with a hydrogenotrophic methanogen (M. hungatei). Mineralization of the aromatic nucleus was achieved with tri- or disubstituted compounds (TMC, sinapate, syringate, and 3,4,5-trimethoxybenzoate) and not with monosubstituted methoxyaromatic compounds (ferulate and vanillate). In addition, the ring of 3,4-dimethoxycinnamate was not cleaved by strain SYR ${ }^{T}$, indicating that the position of methoxysubstitutes on the aromatic compound is of importance for cleavage. The degradation of 3,4-dimethoxybenzoate, vanillate, and ferulate led to the accumulation of acetate and catechol. We have not performed most-probable-number assays and therefore cannot predict with certainty whether strain SYR $^{\mathrm{T}}$ plays a major ecologically important role in the hindgut of $N$. lujae. However, we have extended our knowledge of the microbial biodiversity of termite hindguts and have also demonstrated that termites are an important ecosystem from which unusual microorganisms involved in the degradation of aromatic compounds can be isolated.

It has been suggested that microbial symbionts could play a role in the metabolism of some lignin compounds (21). Among a diverse range of available lignin-derived compounds, the most widely studied has been the fermentation of aromatic compounds in the termite gut $(6,7)$. In almost all cases studied to date, bacteria (e.g., S. termitida) are involved in the demethylation of methoxylated aromatic compounds (8). Recently, Brauman and Garcia (5) have reported a new sporulating anaerobe isolated from the soil-feeding termite Cubitermes speciosus which ferments 3-hydroxybenzoate to acetate and butyrate. Theirs was the first report of a termite bacterium which had the ability to cleave the aromatic ring anaerobically in the absence of chemical or biological electron acceptors. In contrast, strain SYR ${ }^{\mathrm{T}}$, which has been isolated from the hindgut of a wood-feeding termite, produces only acetate by cleav- ing the TMC aromatic ring in the absence of oxygen. Strain $S \mathrm{YR}^{\mathrm{T}}$ clearly differs from the former strain as it does not ferment 3-hydroxybenzoate and produces acetate as the only fatty acid detected from aromatic compound metabolism (5).

A great variety of aerobic and anaerobic bacteria are able to produce DMS from methionine degradation. DMS can also be formed from $S$-methyl-methionine present in various terrestrial plants. Bak et al. (2) were the first to report the production of DMS from aromatic compound degradation by a new anaerobic strain isolated from anoxic sediments which was subsequently designated $H$. foetida (32). This trait is similar to that observed for strain SYR ${ }^{\mathrm{T}}$. However, our experiments further indicate that DMS and methanethiol can be formed not only from inorganic sulfide but also from organic sulfides such as cysteine. The biochemical mechanism by which the methylated sulfur compounds are formed is still unknown.

Other similarities between $H$. foetida and strain $\mathrm{SYR}^{\mathrm{T}}$ include the ability to ferment methoxylated aromatic compounds such as 3,4,5-trimethoxybenzoate, syringate, sinapate, and ferulate, but not $\mathrm{H}_{2}$ plus $\mathrm{CO}_{2}$, methanol, or other alcohols. However, unlike $H$. foetida, strain $\mathrm{SYR}^{\mathrm{T}}$ is a gram-positive spore former and does not use phenolic compounds, particularly gallate and pyrogallol, or pyruvate and has a $\mathrm{G}+\mathrm{C}$ content of $57 \mathrm{~mol} \%$, which is lower than that of $H$. foetida $(63 \mathrm{~mol} \%)$. Phylogenetically, $H$. foetida and strain SYR ${ }^{\mathrm{T}}$ are also different; $H$. foetida has been placed tentatively with members of the delta subclass of Proteobacteria, whereas strain SYR ${ }^{\mathrm{T}}$ is clearly a member of the subbranch of the low-G+C gram-positive clostridial group.

Phylogenetically, strain SYR ${ }^{\mathrm{T}}$, together with $E$. desmolans and $E$. plautii, is peripherally located within the radiation of the clostridial members of cluster III (14). However, strain SYR ${ }^{\mathrm{T}}$ appears to be affiliated to, but not specifically related to, either $E$. desmolans or E. plautii, as the evolutionary distance separating them is an average of 13.2 (Table 1). Physiologically, $E$. plautii and $E$. desmolans are very different from strain $S \mathrm{SR}^{\mathrm{T}}$. 


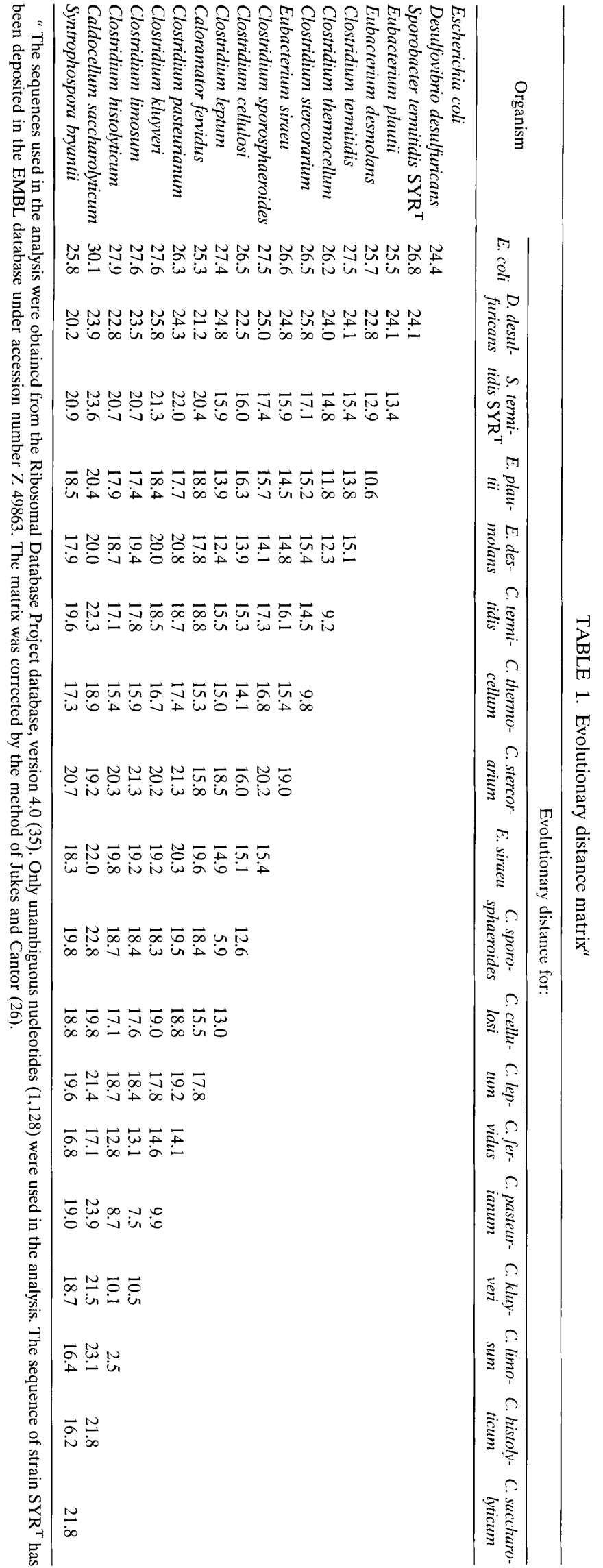

E. plautii cannot use aromatic compounds but uses carbohydrates and produces butyrate and lactate as fermentation end products, whereas $E$. desmolans cannot utilize aromatic compounds or carbohydrates but is able to split off the side chains of steroids (e.g., cortisol) and produces butyrate and lactate as end products. Currently, at least 60 species of Eubacterium have been described on the basis of common characteristics such as morphology (gram-positive nonsporulating rods), anaerobiosis, similar cultural conditions, and the absence of propionate, lactate, and succinate as end products of carbohydrate fermentation (1). However, the wide range of genomic DNA base ratios ( 31 to $55 \mathrm{~mol} \% \mathrm{G}+\mathrm{C}$ ) and recent phylogenetic analysis of the 16S rRNA and 16S rDNA sequences of 33 species available from the Ribosomal Database Project, version 5.0 (35), have indicated that they do not form a cohesive phylogenetic group but are distributed as members of various subbranches of the high- and low-G $+\mathrm{C}$ branches of the gram-positive phylum.

Phenotypically, strain SYR ${ }^{\mathrm{T}}$ is also distinct from members of the remaining 28 Eubacterium species, whose $16 \mathrm{~S}$ rRNA data are not available, as most use carbohydrates (and have a $\mathrm{G}+\mathrm{C}$ content of less than 45\%), with the exception of Eubacterium oxidoreducens and Eubacterium callanderi (1). E. oxidoreducens is a rumen isolate which degrades trihydroxybenzenoids such as gallate, pyrogallol, phloroglucinol, and quercetin in the presence of an external electron donor such as $\mathrm{H}_{2}$ or formate, but not for crotonate degradation, whereas E. callanderi, a sewage isolate, is able to demethylate aromatic methoxylated acids such as ferulate, sinapate, syringate, vanillate, and TMC to produce the corresponding hydroxyaromatic derivate and acetate, butyrate, and formate; in addition, lactate and $\mathrm{H}_{2}$ are produced from glucose fermentation. Mountfort et al. (37) have suggested that E. callanderi may be related to Eubacterium limosum, as they have the same $\mathrm{G}+\mathrm{C}$ content, both demethylate aromatic compounds, and are homologous by DNA-DNA hybridization studies. Phylogenetic studies place E. limosum with Clostridium barkeri in the clostridial cluster XV, distinctly different from that of strain SYR ${ }^{\mathbf{T}}$, which is located as a peripheral member of cluster III.

Absolute boundaries, based on 16S rRNA sequence information, have not been proposed for defining a genus, species, or higher taxon, nor is it appropriate to do so, as it is known that the rate of change in the $16 \mathrm{~S}$ rDNA differs for different groups of organisms. Therefore, a working taxonomy must take into consideration both the phenotype and the phylogenetic position of the organism (coined as the polyphasic approach to taxonomy).

On the basis of the combination of distinct phylogenetic position and physiological properties, we propose that strain $\mathrm{SYR}^{\mathrm{T}}$ be assigned to a new genus, Sporobacter gen. nov., and a new species, $S$. termitidis gen. nov., sp. nov.

Description of Sporobacter gen. nov. Spo.ro.bac'ter. M.L. n. spora, spore; M.L. n. bacter, masc. equivalent of Gr. neut. n. bakterion, rod; M.L. n. masc. Sporobacter, a spore-forming rod. Gram positive, strictly anaerobic. Produces methylated sulfides from methylated aromatic compounds if sulfide or cysteine is present in the medium, with acetate being the only volatile fatty acid produced from this metabolism. External electron acceptors are not used.

Description of Sporobacter termitidis gen. nov., sp. nov. ter. mi'ti.dis. M.L. n. masc. tarmes, tarmit- (L.L. var. termes, termit-), wood-eating worm; M.L. adj. termitidis, pertaining to the termite. Cells are slightly curved rods, 0.2 to 0.4 by 1 to $2 \mu \mathrm{m}$, possessing peritrichous flagella. Gram positive. Terminal spore swelling the sporange. Obligate anaerobe. Optimum growth temperature between 32 and $35^{\circ} \mathrm{C}$; range, 20 to $40^{\circ} \mathrm{C}$. Optimum $\mathrm{pH}$ between 6.7 and 7.2 ; range, 5.9 to 8.8 . Growth between 0 and $5 \mathrm{~g}$ of $\mathrm{NaCl}$ liter $^{-1}$; inhibited at $12.5 \mathrm{~g}$ of $\mathrm{NaCl}$ 
$\operatorname{liter}^{-1}$. Yeast extract $(0.01 \%)$ is required for growth. Doubling time of $25 \mathrm{~h}$ under optimal conditions.

Substrates used as sole energy source: TMC, sinapate (3,5dimethoxy-4-hydroxycinnamate), 3,4-dimethoxycinnamate, 3,4,5-trimethoxybenzoate, ferulate, syringate (3,5-dimethoxy4-hydroxybenzoate), vanillate (4-hydroxy-3-methoxybenzoate).

Substrates not used: veratrate, isovanillate, benzoate, $\beta$-resorcylate (2,4-dihydroxybenzoate), gentisate (2,5-dihydroxybenzoate), vanillin (4-hydroxy-3-methoxybenzaldehyde), 4-hydroxybenzoate, 2,4,6-trihydroxybenzoate, protocatechuate, cinnamate, $p$-coumarate, 4-methoxycinnamate, pyrogallol, gallate, caffeate, phenol, $o$-cresol, $p$-cresol, catechol, salicin, arbutin, phloroglucinol, cyclohexanecarboxylate, hydrocinnamate, phenylacetate, fructose, galactose, glucose, ribose, xylose, lactose, maltose, sucrose, trehalose, mannitol, rhamnose, sorbose, melibiose, ribitol, galactitol, D-glucitol, pyruvate, lactate, formate, ethanol, methanol, glycerol, $\mathrm{H}_{2}-\mathrm{CO}_{2}$.

Produces acetate, DMS, and methanethiol from TMC in the presence of sulfide or cysteine.

The $\mathrm{G}+\mathrm{C}$ content of the DNA is $57 \mathrm{~mol} \%$ (determined by HPLC). Peripherally related to the members of clostridial cluster III.

Type strain SYR ${ }^{\mathrm{T}}$ is deposited in the DSM under accession number 10068. It was isolated from the hindgut of the woodfeeding termite $N$. lujae.

\section{ACKNOWLEDGMENTS}

We thank K. D. Jahnke and J. Burghardt (DSM, Braunschweig, Germany) for the determination of the DNA G+C content and J. L. Cayol for helpful discussion. B. Chung and A. Eagan are thanked for their assistance in sequencing.

Funding in part from the Australian Research Council (to B.K.C.P.) is gratefully acknowledged.

\section{REFERENCES}

1. Andreesen, J. R. 1991. The genus Eubacterium, p. 1914-1924. In A. Balows, H. G. Trüper, M. Dworkin, W. Harder, and K.-H. Schleifer (ed.), The prokaryotes, 2nd ed., vol. II. Springer-Verlag, New York.

2. Bak, F., K. Finster, and F. Rothfuß. 1992. Formation of dimethylsulfide and methanethiol from methoxylated aromatic compounds and inorganic sulfide by newly isolated anaerobic bacteria. Arch. Microbiol. 157:529-534.

3. Bignell, D. E. 1984. Direct potentiometric determination of redox potentials of the gut contents in the termites Zootermopsis nevadensis and Cubitermes severus and in three other arthropods. J. Insect Physiol. 30:169-174.

4. Bignell, D. E., and J. M. Anderson. 1980. Determination of $\mathrm{pH}$ and oxygen status in the guts of lower and higher termites. J. Insect Physiol. 26:183-188.

5. Brauman, A., and J. L. Garcia. 1991. Isolation of a new 3-hydroxybenzoatefermenting bacterium from hindguts of a soil-feeding termite, Cubitermes speciosus, abstr. I-12, p. 192. In Abstracts of the 91st General Meeting of American Society for Microbiology 1991. American Society for Microbiology, Washington, D.C.

6. Brauman, A., M. D. Kane, M. Labat, and J. A. Breznak. 1992. Genesis of acetate and methane by gut bacteria of nutritionally diverse termites. Science 257:1384-1387.

7. Breznak, J. A., and A. Brune. 1994. Role of microorganisms in the digestion of lignocellulose by termites. Annu. Rev. Entomol. 39:453-487.

8. Breznak, J. A., and J. M. Switzer. 1986. Acetate synthesis from $\mathrm{H}_{2}$ plus $\mathrm{CO}_{2}$ by termite gut microbes. Appl. Environ. Microbiol. 52:623-630.

9. Breznak, J. A., J. M. Switzer, and H. J, Seitz. 1988. Sporomusa termitida $\mathrm{sp}$ nov., an $\mathrm{H}_{2} / \mathrm{CO}_{2}$-utilizing acetogen isolated from termites. Arch. Microbiol. 150:282-288.

10. Brune, A., J. A. Breznak, and A. Brauman. 1992. Metabolism of aromatic compounds by wood and soil feeding termites; involvement of the intestinal microflora, p. 126. In Proceedings of the 6th International Symposium on Microbial Ecology.

11. Brune, A., D. Emerson, and J. A. Breznak. 1995. The termite gut microflor as an oxygen sink: microelectrode determination of oxygen and $\mathrm{pH}$ gradients in guts of lower and higher termites. Appl. Environ. Microbiol. 61:2681-2687.

12. Brune, A., E. Miambi, and J. A. Breznak. 1995. Roles of oxygen and the intestinal microflora in the metabolism of lignin-derived phenylpropanoids and other monoaromatic compounds by termites. Appl. Environ. Microbiol. 61:2688-2695.
13. Butler, J. H., and J. C. Buckerfield. 1979. Digestion of lignin by termite. Soil Biol. Biochem. 11:507-513.

14. Collins, M. D., P. A. Lawson, A. Willems, J. J. Cordoba, J. FernandezGarayzabal, P. Garcia, J. Cai, H. Hippe, and J. A. E. Farrow. 1994. The phylogeny of the genus Clostridium: proposal of five new genera and eleven new species combinations. Int. J. Syst. Bacteriol. 44:812-826.

15. Cookson, L. J. $1987 .{ }^{14} \mathrm{C}$ lignin degradation by three Australian termite species. Wood Sci. Technol. 21:11-25.

16. Cookson, L. J. 1988. The site of mechanism of ${ }^{14} \mathrm{C}$ lignin degradation by Nasutitermes exitiosus. J. Insect Physiol. 34:409-414.

17. Diekert, G., and G. Wohlfarth. 1994. Metabolism of homoacetogens. Antonie Leeuwenhoek 66:209-221.

18. Fardeau, M. L., J. L. Cayol, M. Magot, and B. Ollivier. 1993. $\mathbf{H}_{2}$ oxidation in the presence of thiosulfate by a Thermoanaerobacter strain isolated from an oil-producing well. FEMS Microbiol. Lett. 113:327-332.

19. Felsentein, J. 1993. PHYLIP (phylogenetic interference package) version 3.51c. Department of Genetics, University of Washington, Seattle.

20. Grasse, P. P. 1982. Anatomie, physiologie, reproduction des termites. In Termitologia, tome I. Masson, Paris.

21. Grasse, P. P., and C. Noirot. 1959. L'évolution de la symbiose chez les isoptères. Experientia 15:365-372.

22. Hethener, P., A. Brauman, and J.-L. Garcia. 1992. Clostridium termitidis sp. nov., a cellulolytic bacterium from the gut of the wood-feeding termite, Nasutitermes lujae. Syst. Appl. Microbiol. 15:52-58.

23. Hungate, R. E. 1969. A roll-tube method for the cultivation of strict anaerobes. Methods Microbiol. 3B:117-132.

24. Imhoff-Stuckle, D., and N. Pfennig. 1983. Isolation and characterization of a nicotinic acid-degrading sulfate-reducing bacterium, Desulfococcus niacini sp. nov. Arch. Microbiol. 136:194-198.

25. Ioffe, B. V., and A. G. Vitenberg. 1984. Head-space analysis and related methods in gas chromatography. John Wiley and Sons, Inc., New York.

26. Jukes, T. H., and C. R. Cantor. 1969. Evolution of protein molecules, p 21-132. In H. N. Munro (ed.), Mammalian protein metabolism. Academic Press, Inc., New York.

27. Kane, M. D., and J. A. Breznak. 1991. Acetonema longum gen. nov, sp. nov., an $\mathrm{H}_{2} / \mathrm{CO}_{2}$ acetogenic bacterium from the termite, Pterotermes occidentis. Arch. Microbiol. 156:91-98.

28. Kreft, J. U., and B. Schink. 1993. Demethylation and degradation of phenylmethylethers by the sulfide methylating homoacetogenic bacterium strain $\mathrm{TMBS}_{4}$. Arch. Microbiol. 159:308-315.

29. Kuhnigk, T., E. M. Borst, A. Ritter, P. Kämpfer, A. Graf, H. Hertel, and H. König. 1994. Degradation of lignin monomers by the hindgut microflora of xylophagous termites. Syst. Appl. Microbiol. 17:76-85.

30. Kumar, S., K. Tamura, and M. Nei. 1993. MEGA: molecular evolutionary genetic analysis, version 1.0. The Pennsylvania State University, University Park.

31. Lee, K. E., and T. G. Wood. 1971. Termites and soils. Academic Press, New York.

32. Liesack, W., F. Bak, J. U. Kreft, and E. Stackebrandt. 1994. Holophaga foetida gen. nov., sp. nov., a new homoacetogenic bacterium degrading methoxylated aromatic compounds. Arch. Microbiol. 162:85-90.

33. Love, C. A., B. K. C. Patel, P. D. Nichols, and E. Stackebrandt. 1993. Desulfotomaculum australicum sp. nov., a thermophilic sulfate-reducing bacterium isolated from the Great Artesian Basin of Australia. Syst. Appl. Microbiol. 16:244-251.

34. Macy, J. M., J. E. Snellen, and R. E. Hungate. 1972. Use of syringe methods for anaerobiosis. Am. J. Clin. Nutr. 25:1318-1323.

35. Maidak, B. L., N. Larsen, M. J. McCaughey, R. Overbeek, G. J. Olsen, K. Fogel, J. Blandy, and C. R. Woese. 1994. The ribosomal database project. Nucleic Acids Res. 22:3485-3487.

36. Meshbah, M., U. Premachandran, and W. Whitman. 1989. Precise measurement of the $\mathrm{G}+\mathrm{C}$ content of deoxyribonucleic acid by high-performance liquid chromatography. Int. J. Syst. Bacteriol. 39:159-167.

37. Mountfort, D. O., W. D. Grant, R. Clarke, and R. A. Asher. 1988. Eubacterium callanderi $\mathrm{sp}$. nov. that demethoxylates $o$-methoxylated aromatic acids to volatile fatty acids. Int. J. Syst. Bacteriol. 38:254-258.

38. Noirot, C., and C. Noirot-Timothee. 1969. The digestive system, p. 49-88. In K. Krishna and M. Weesner (ed.), Biology of termites, vol. 1. Academic Press, New York.

39. Novak, J. 1975. Quantitative analysis by gas chromatography. Marcel Dekker, New York

40. Odelson, D. A., and J. A. Breznak, 1983. Volatile fatty acid production by the hindgut microbiota of xylophagous termites. Appl. Environ. Microbiol. 45: $1602-1613$

41. Redburn, A. C., and B. K. C. Patel. 1993. Phylogenetic analysis of Desulfotomaculum thermobenzoicum using polymerase chain reaction-amplified $16 \mathrm{~S}$ rRNA-specific DNA. FEMS Microbiol. Lett. 113:81-86.

42. Reynolds, E. S. 1963. The use of lead citrate at high $\mathrm{pH}$ as an electron opaque stain in electron microscopy. J. Cell Biol. 17:208-212.

43. Winker, S., and C. R. Woese. 1991. A definition of the domains Archaea, Bacteria and Eucarya in terms of small subunit ribosomal RNA characteristics. Syst. Appl. Microbiol. 13:161-165. 